\title{
STUDIES OF FERROELECTRIC HETEROSTRUCTURE THIN FILMS AND INTERFACES VIA IN SITU ANALYTICAL TECHNIQUES*
}

\author{
O. Auciello ${ }^{1}$ A. R. Krauss ${ }^{2}$, J. $\operatorname{Im}^{1}$, A. M. Dhote, ${ }^{2,3}$, D. M. Gruen ${ }^{2}$, \\ E. A. Irene ${ }^{3}$, Y. Gao ${ }^{3}$, A. H. Muller ${ }^{3}$, and R. Ramesh ${ }^{4}$ \\ ${ }^{1}$ Materials Science Division \\ ${ }^{2}$ Chemistry Division \\ Argonne National Laboratory \\ Argonne, IL 60439 \\ ${ }^{3}$ University of North Carolina \\ Department of Chemistry \\ Chapel Hill, NC 27599 \\ ${ }^{4}$ University of Maryland

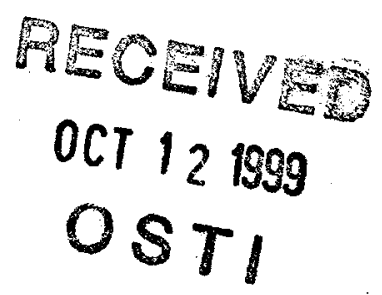 \\ Dept. of Materials and Nucl. Engr.
}

College Park, MD 20742

\section{August 1999}

The submitted manuscript has been created
by the University of Chicago as Operator of
Argonne National Laboratory ("Argonne"
under Contract No. W-31-109-ENG-38 with
the U.S. Department of Energy. The U.S.
Government retains for itself, and others
acting on its behalf, a paid-up, non exclusive,
irrevocable worldwide license in said article to
reproduce, prepare derivative works, distribute
copies to the public, and perform publicly and
display publicly, by or on behalf of the
Government.

Invited paper to be submitted for publication in Integrated Ferroelectrics as the proceedings of the International Workshop on Ferroelectric and High Dielectric Thin Films, San Juan, Puerto Rico, May 12-15, 1999.

*We wish to acknowledge support from the U. S. Department of Energy, BES-Materials Sciences, under Contract W-31-109-ENG-38, the National Science Foundation under contract DMR 942-2182, and the Office of Naval Research under contract N00014-89-J-1178. 


\section{DISCLAIMER}

This report was prepared as an account of work sponsored by an agency of the United States Government. Neither the United States Government nor any agency thereof, nor any of their employees, make any warranty, express or implied, or assumes any legal liability or responsibility for the accuracy, completeness, or usefulness of any information, apparatus, product, or process disclosed, or represents that its use would not infringe privately owned rights. Reference herein to any specific commercial product, process, or service by trade name, trademark, manufacturer, or otherwise does not necessarily constitute or imply its endorsement, recommendation, or favoring by the United States Government or any agency thereof. The views and opinions of authors expressed herein do not necessarily state or reflect those of the United States Government or any agency thereof. 


\section{DISCLAIMER}

Portions of this document may be illegible in electronic image products. Images are produced from the best available original document. 


\title{
STUDIES OF FERROELECTRIC HETEROSTRUCTURE THIN FILMS AND INTERFACES, VIA IN SITU ANALYTICAL TECHNIQUES
}

\author{
ORLANDO AUCIELLO, ${ }^{1}$ ALAN R. KRAUSS, ${ }^{2}$ JAEMO IM, ${ }^{1}$ \\ ANIL DHOTE,,$^{2,3}$ DIETER $M$. GRUEN, ${ }^{2}$ EUGENE A. IRENE, ${ }^{3}$ \\ YING GAO, ${ }^{3}$ ALEX H. MUELLER, ${ }^{3}$ and RAMAMOORTHY RAMESH ${ }^{4}$ \\ 'Argonne National Laboratory, Materials Science Division, Argonne, IL 60439; \\ ${ }^{2}$ Argonne National Laboratory, Materials Science and Chemistry Divisions, \\ Argonne, IL 60439; ${ }^{4}$ University of North Carolina, Department of Chemistry, \\ Chapel Hill, NC 27599; ${ }^{4}$ University of Maryland, Materials and Nuclear \\ Engineering , College Park, MD 20742
}

The science and technology of ferroelectric thin films has experienced an explosive development during the last ten years. Low-density non-volatile ferroelectric random access memories (NVFRAMs) are now incorporated in commercial products such as "smart cards", while high permittivity capacitors are incorporated in cellular phones. However, substantial work is still needed to develop materials integration strategies for high-density memories. We have demonstrated that the implementation of complementary in situ characterization techniques is critical to understand film growth and interface processes, which play critical roles in film microstructures and properties.

We are using uniquely integrated time of flight ion scattering and recoil spectroscopy (TOF-ISARS) and spectroscopic ellipsometry (SE) techniques to perform in situ, real-time studies of film growth processes in the high background gas pressure required to growth ferroelectric thin films. TOFISARS provides information on surface processes, while SE permits the investigation of buried interfaces as they are being formed. Recent studies on $\mathrm{SrBi}_{2} \mathrm{Ta}_{2} \mathrm{O} 9$ (SBT) and $\mathrm{Ba}_{x} \mathrm{Sr}_{1-\mathrm{x}} \mathrm{TiO}_{3}$ (BST) film growth and interface processes are discussed.

Keywords: in situ characterization, ferroelectric films, ion scattering, recoil spectroscopy, spectroscopic ellipsometry, SFM piezoresponse, X-ray scattering

\section{INTRODUCTION}

Ferroelectric and high dielectric constant (k) thin films, relevant to non-volatile ferroelectric random access memories (NVFRAMs) and high (k) dynamic random access memories (DRAMs), respectively, will be very thin $(<100 \mathrm{~nm})$ for the next generation of high density, low voltage devices. In addition, as the heterostructure ferroelectric capacitors needed for these memories and 


\section{O. AUCIELLO et al.}

processing conditions become increasingly more complex, there is a growing need for in situ, real-time, surface-specific analytical tools to characterize phenomena occurring at the surface of the growing films and heterostructure interfaces. These analytical tools must not be destructive, should provide a wide range of surface compositional and structural information on a time scale commensurate with the deposition rate, and must be compatible with the geometric constraints of the deposition process and the temperatures and ambient gas pressures required by the thin film growth environment.

We are focusing our research on investigating two materials that play critical roles in NVFRAMs $\left[\mathrm{SrBi}_{2} \mathrm{Ta}_{2} \mathrm{O}_{9}\right.$ and DRAMs and high frequency devices $\left[\mathrm{Ba}_{\mathrm{x}} \mathrm{Sr}_{1-\mathrm{x}} \mathrm{TiO}_{3}\right.$ (BST)].

We have demonstrated that an appropriate combination of three low-keV ion beam spectroscopies, $x$-ray photoelectron spectroscopy, and/or spectroscopic ellipsometry can be used to provide an exceptionally wide range of surface and interface compositional, structural and chemical information related to the synthesis of ferroelectric films. In addition, we have demonstrated that an appropriate combination of in situ or in situ, real-time characterization techniques can provide valuable information to aid in the understanding of polarization dynamics critical to the operation of ferroelectric thin film-based devices. This review provides information related to recent work that demonstrate the power of using in situ and/or in situ, real-time characterization techniques to elucidate film growth and surface and interface related processes that are critical to the development of materials integration strategies for the present and next generation of ferroelectric thin film-based devices.

\section{IN SITU STUDIES OF FILMS VIA TIME-OF-FLIGHT ION SCATTERING AND RECOIL SPECTROSCOPY (TOF-ISARS)}

\section{Background on TOF-ISARS}

The fundamental and experimental bases of the complementary time-of-flight ion scattering and recoil spectroscopy techniques (TOF-ISARS) discussed in this paper have been described in detail in our prior publications ${ }^{[1,2]}$. Briefly, an ion beam with a kinetic energy of several $\mathrm{keV}$ is incident upon the surface to be studied. At these kinetic energies, the collision kinematics are essentially those of classical two body elastic collisions.

In low energy ion scattering spectroscopy (ISS), the mass of a surface atom is determined by measuring the kinetic energy loss of a primary ion of known mass, which scatters from a single surface atom. ISS is a wellestablished surface analysis technique ${ }^{[3,4]}$, and is the most surface-specific of the surface analytical methods, with a depth sensitivity, which can be limited to one atomic layer.

In our system, the kinetic energy of the backscattered primary particle is measured by pulsing the beam and using a time of flight (ToF) detection scheme. A typical analysis beam dose for ToF detection is $\sim 10^{11}-10^{12}$ ions $/ \mathrm{cm}^{2}$, removing or displacing 1 part in $10^{3}-10^{4}$ of the near-surface atoms and making the ToF scheme essentially non-destructive ${ }^{[1,5]}$.

Direct Recoil Spectroscopy (DRS) has been in use in a number of laboratories for several years ${ }^{[6-8]}$, and benefited from recent improvements in 


\section{IN SITU STUDIES OF FERROELECTRIC FILMS AND DEVICEPROCESS}

time of flight instrumentation ${ }^{[9]}$. DRS employs relatively grazing entrance and exit angles to eject surface atoms via a single collision event with the primary ion. The ejected surface atoms are detected by a particle counter such as a channel plate multiplier, and the beam forming and detection hardware are very similar to that of ISS. The principal advantage of DRS compared with ISS is the ability of the former method to detect all atomic species, even those, which are lighter than the primary ion, including hydrogen.

Mass Spectroscopy of Recoiled Ions (MSRI) ${ }^{[2,5,10]}$ is a variation of DRS in which only the ion fraction of the direct recoil spectrum is detected. It is similar to secondary ion mass spectroscopy (SIMS) except that the DRS geometry is chosen to emphasize single collision ejection events, rather than the multiple collision cascade mechanism associated with the SLMS process. Consequently, the kinetic energy and ion-fraction of the ejected surface atoms are much higher than for SIMS.

The TOF-ISARS techniques are based on classical collision theory discussed in prior publications ${ }^{[1,2,10]}$. A schematic of the fundamental principles is shown in Fig. 1, and a detailed discussion can be found in prior publications $[2,10]$ and in these proceedings ${ }^{[11]}$. Briefly, the chamber is split into two sections. Auger electron spectroscopy (AES) and $x$-ray photoelectron spectroscopy (XPS) are included in the upper chamber to perform immediate post-deposition surface analysis as a complement to the TOF-ISARS studies of growth processes. Thin film deposition is accomplished in the lower chamber by means of a $3-\mathrm{cm}$ Kaufmann ion gun which is focused onto a target mounted on a rotating carousel with multiple targets. The use of differential pumping methods to perform TOF-ISARS characterization of film growth processes in high-pressure environments was described in one of our prior papers ${ }^{[12]}$.

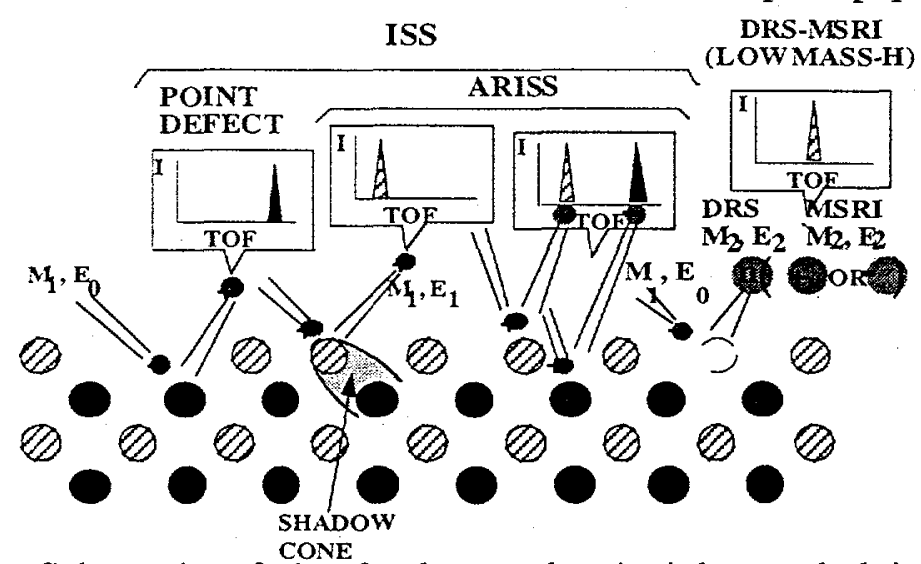

FIGURE 1. Schematic of the fundamental principles underlying the TOFISARS techniques: ISS; including angular-resolved ion scattering spectroscopy (ARISS), which provides information about surface structure; DRS; and MSRI.

The combined use of ISS and DRS techniques described above provides the means for measuring the surface composition ${ }^{[7]}$ with excellent sensitivity for trace elements ${ }^{[1]}$, including hydrogen ${ }^{[1]]}$, and determination of the local surface geometry ${ }^{[14]}$ and chemical phase. It is also possible to distinguish layer- by -layer growth in thin films from $2 \mathrm{D}$ and $3 \mathrm{D}$ island formation ${ }^{[15]}$. It is also 


\section{O. AUCIELLO et al.}

possible to obtain information on surface disorder, including the presence of point defects and surface phonon dispersion, under special analysis conditions.

Although the experimental work described in this chapter is focused on multicomponent oxide ferroelectric thin films and heterostructures, the TOFISARS technique has also been successfully used to study surface processes of materials such as high temperature superconductors ${ }^{[16]}$, semiconductors ${ }^{[16]}$ and diamond ${ }^{[17]}$.

Studies of Film Growth and Interface Processes Relevant to Ferroelectric Capacitors

Due to space constrains, we can only present selected examples of TOF-ISARS studies performed in the last five years. Data related to the growth of SBT and BST films is presented and discussed as a means of illustrating previously discussed capabilities of the methods to study ferroelectric film growth and surface and interface processes.

\section{In Situ Analysis of SBT/Bottom Electrode Interfaces and SBT} Initial Growth Stages

Recently, there has been extensive interest in the synthesis of ferroelectric layered perovskite thin films such as $\mathrm{SrBi}_{2} \mathrm{Ta}_{2} \mathrm{O}_{9}$ (SBT) for application to NVFRAMs. Pt/SBT/Pt capacitors show practically no polarization fatigue, little imprint, and memory-compatible retention ${ }^{[18]}$. Platinum is simple to deposit and has a much lower electrical resistivity than oxide electrodes needed for fatiguefree PZT-based capacitors ${ }^{[13]}$, resulting in short RC time constants and high device speed. The ability to use $\mathrm{Pt}$ electrodes and the properties already demonstrated for Pt/SBT/Pt capacitors make them a favored choice for the first generation of commercial NVFRAMs. Because of the high crystallization temperature of SBT films $\left(>700^{\circ} \mathrm{C}\right)$, integration of SBT- based capacitors with $\mathrm{Si}$ based technology requires a stable bottom electrode / barrier heterostructure. $\mathrm{Pt} / \mathrm{Ti} / \mathrm{SiO}_{2} / \mathrm{Si}$ has been widely used as a bottom electrode heterostructure for ferroelectric capacitors. The Ti layer enhances the adhesion of $\mathrm{Pt}$ on $\mathrm{SiO}_{2}$. Prior studies on the high temperature stability of Pt/Ti layers in an oxygen environment revealed that $\mathrm{Ti}$ diffuses into the $\mathrm{Pt}$ layer along grain boundaries during heating ${ }^{[19.20]}$. If the $\mathrm{Ti}$ segregates to the $\mathrm{Pt}$ surface and is incorporated into the SBT film, it may have an adverse affect on composition, microstructure, and initial stages of film growth, which affect the properties of the SBT-based capacitors. In fact, it has been reported that the electrical properties of SBT capacitors are degraded by the diffused $\mathrm{Ti}$ through $\mathrm{Pt}$ electrodes ${ }^{[21]}$.

Conventional analytical techniques have not been able to clearly describe the state of the Pt surface after heating, or explain how the Pt surface condition (on the monolayer scale) affects the growth of the subsequent SBT film: For example conventional Rutherford Backscattering Spectroscopy (RBS) was used to study the near-surface composition of the $\mathrm{Pt} / \mathrm{Ti} / \mathrm{SiO}_{2} / \mathrm{Si}$ heterostructure substrate during heating to $700^{\circ} \mathrm{C}$ in vacuum. Figure 2 shows the RBS spectra of the $\mathrm{Pt} / \mathrm{Ti} / \mathrm{SiO}_{2} / \mathrm{Si}$ layered heterostructure before and after heating to $700^{\circ} \mathrm{C}$. The spectra clearly show the broadening of the Ti peak, indicating diffusion of 


\section{IN SITU STUDIES OF FERROELECTRIC FILMS AND DEVICEPROCESS}

Ti into the Pt layer. However, the depth resolution of RBS is insufficient to disclose whether Ti appears at the surface of the Pt layer.

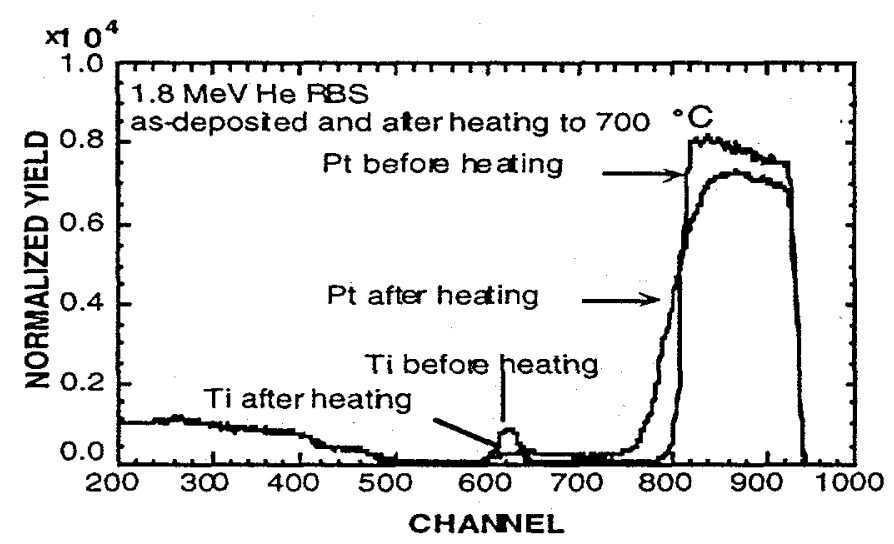

FIGURE 2. RBS spectrum for a Pt/Ti electrode before and after $700^{\circ} \mathrm{C}$ anneal.

MSRI was used to obtain a clearer picture of surface segregation phenomena than that provided by RBS. As shown in Fig. 3, the surface composition in vacuum at room temperature is dominated by $\mathrm{H}, \mathrm{C}, \mathrm{O}, \mathrm{Pt}, \mathrm{Ar}$ (backscattered primary ions), and a small amount of Ti. Currently, the MSRI peak intensity cannot be correlated to the surface concentration. In addition, because of its relative chemical inertness and high mass, the sensitivity for $\mathrm{Pt}$ is lower than that for $\mathrm{Ti}, \mathrm{Si}$, and $\mathrm{H}$. However, as the temperature increases (Fig. 3(b)) and 3(c)), the Pt signal decreases and nearly disappears, while at the same time the $\mathrm{Ti}$ signal increases significantly and a Si peak appears. From the decrease in the $\mathrm{Pt}$ signal, it may be estimated that at least $80 \%$ of the $\mathrm{Pt}$ surface consists of segregated $\mathrm{Ti}$ and Si due to heating at $700^{\circ} \mathrm{C}$.

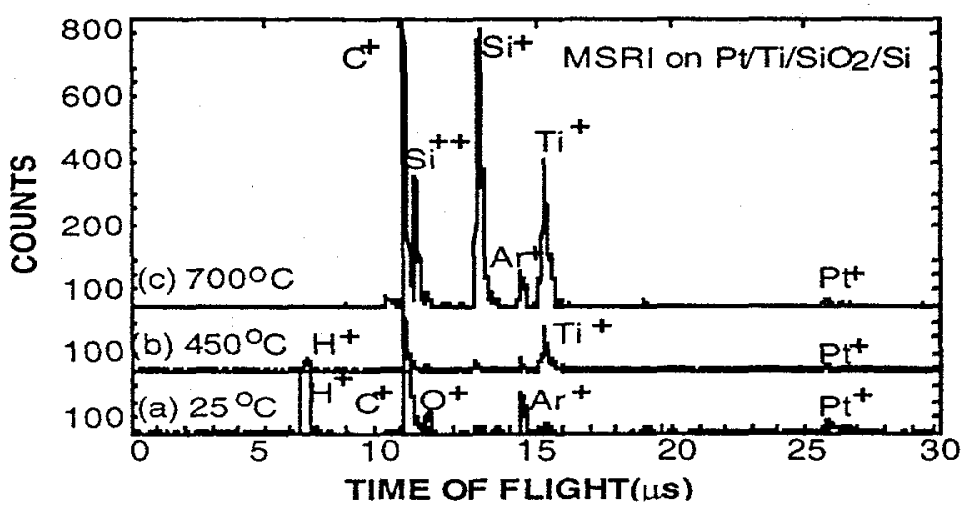

FIGURE 3. Segregation processes in the $\mathrm{Pt} / \mathrm{Ti} / \mathrm{SiO}_{2} / \mathrm{Si}$ heterostructure bottom electrode system heated in vacuum, as observed using MSRI analysis.

When the $\mathrm{Pt} / \mathrm{Ti} / \mathrm{SiO}_{2} / \mathrm{Si}$ heterostructure is heated in $5 \times 10^{-4}$ Torr of oxygen, Ti appears on the Pt surface at $\sim 400^{\circ} \mathrm{C}$, but very little Si appears even 
at $700^{\circ} \mathrm{C}$. We attributed this effect to the formation of a $\mathrm{TiO}_{\mathrm{x}}$ layer at the $\mathrm{Ti} / \mathrm{Si}$ interface as a result of oxygen diffusion via $\mathrm{Pt}$ grain boundaries. The $\mathrm{TiO}_{\mathrm{x}}$ layer provides a good diffusion barrier for $\mathrm{Si}^{[20]}$. To test this hypothesis, a $\mathrm{TiO}_{2}$ film was grown on a $\mathrm{SiO}_{2} / \mathrm{Si}$ substrate and subsequently covered with a $\mathrm{Pt}$ layer. The Pt $/ \mathrm{TiO}_{2} / \mathrm{SiO}_{2} / \mathrm{Si}$ structure was subsequently heated in $5 \times 10^{-4}$ Torr of oxygen. The MSRI spectra in Fig. 4 show that there is neither $\mathrm{Ti}$ nor $\mathrm{Si}$ segregation to the $\mathrm{Pt}$ surface up to $700^{\circ} \mathrm{C}$, indicating the stability of the $\mathrm{Pt} / \mathrm{TiO}_{2}$ electrode, as shown also by other groups ${ }^{[20,22]}$.

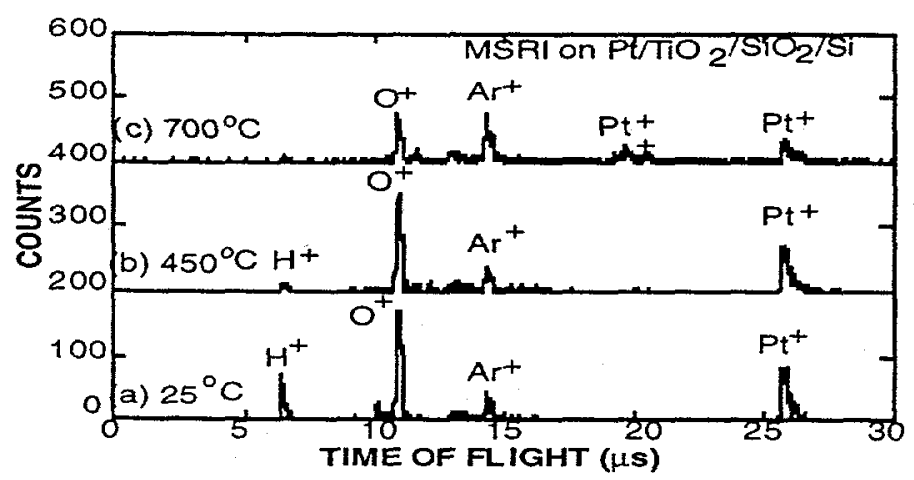

FIGURE 4. MSRI analysis of a $\mathrm{Pt} / \mathrm{TiO}_{2} / \mathrm{SiO}_{2} / \mathrm{Si}$ heterostructure during heating to $700^{\circ} \mathrm{C}$ in $5 \times 10^{-4}$ Torr of oxygen.

We also investigated the thermal stability of $\mathrm{Pt} / \mathrm{Ta} / \mathrm{SiO}_{2} / \mathrm{Si}, \mathrm{Ir} / \mathrm{SiO}_{2} / \mathrm{Si}$ and $\mathrm{RuO}_{2} / \mathrm{SiO}_{2}$ heterostructures, in order to see if $\mathrm{Ta}$, Ir, and $\mathrm{RuO}_{2}$ provide more stable adhesion-diffusion barrier layers than $\mathrm{Ti}$ for the integration of $\mathrm{Pt}$ with $\mathrm{Si}$. Additionally, Ta is not an impurity for SBT films even if Ta diffuses to the $\mathrm{Pt}$ surface during heating, although excess Ta may affect the stoichiometry and properties of the SBT films. The use of Ta may facilitate elimination of the oxidation processing step required to stabilize the Ti layer in the $\mathrm{Pt} / \mathrm{Ti} / \mathrm{SiO} / \mathrm{Si}$ heterostructure. MSRI analysis showed that Ta diffuses to the surface of $\mathrm{Pt}$ at $700^{\circ} \mathrm{C}$ in an oxygen environment, but no $\mathrm{Si}$ migration to the $\mathrm{Pt}$ surface was observed (Fig. 5(a). In the cases of the $\mathrm{Ir} / \mathrm{SiO}_{2} / \mathrm{Si}$ (Fig. 5(b) and $\mathrm{RuO}_{2} / \mathrm{SiO}_{2}$ (Fig. 5)c) heterostructures, also no Si diffusion to the $\mathrm{Pt}$ surface was observed even if heated up to $700{ }^{\circ} \mathrm{C}$ in oxygen. Fig 5 reveals that the $\mathrm{Ta}$, Ir, and RuObased heterostructure electrodes described above are stable and therefore can provide good alternatives for the integration of SBE thin films with $\mathrm{Si}$ for the fabrication of NVFRAMs. However, further work, particularly involving electrical characterization of SBT capacitors using these electrodes, is necessary to evaluate their suitability for integration into NVFRAMs.

\section{Studies of the Initial Stages of SBT Film Growth via Physical} Vapor-Deposition

Since it has been reported that Ti degrades the electrical properties of SBT based capacitors ${ }^{[2]}$, we studied the initial growth of SBT films on the PtTi and $\mathrm{Pt} / \mathrm{TiO}_{2} / \mathrm{SiO}_{2} / \mathrm{Si}$ electrode layers discussed above. These experiments 


\section{IN SITU STUDIES OF FERROELECTRIC FILMS AND DEVICEPROCESS}

demonstrated that for SBT films sputter-deposited on Pt/Ti electrodes in $5 \times 10^{-4}$ Torr of oxygen at $700^{\circ} \mathrm{C}$, there is negligible incorporation of $\mathrm{Bi}$, in the first 20 $\mathrm{nm}$ of SBT, and significant segregation of $\mathrm{Ti}$ and $\mathrm{Si}$ at the Pt-SBT interface. Once the $\mathrm{Ti}$ and $\mathrm{Si}$ species have been covered by $\mathrm{Sr}$ and $\mathrm{Ta}$ atoms of the growing film, Bi begins to incorporate and the SBT film composition becomes closer to stoichiometric. On the other hand, when SBT is deposited at $700^{\circ} \mathrm{C}$ in $5 \times 10^{-4}$ Torr of oxygen, on a $\mathrm{Pt} / \mathrm{TiO}_{2} / \mathrm{SiO}_{2} / \mathrm{Si}$ heterostructure. MSRI analysis reveals that there is neither $\mathrm{Ti}$ nor $\mathrm{Si}$ segregation on the surface of the $\mathrm{Pt}$ layer, and $\mathrm{Bi}$ is efficiently incorporated in all stages of the growing SBT film. The effect of $\mathrm{Ti}$ and $\mathrm{Si}$ surface species on $\mathrm{Bi}$ incorporation can be explained by the fact that both $\mathrm{Ti}$ and $\mathrm{Si}$ have larger (negative) magnitude of oxide formation energy than $\mathrm{Bi}^{[23,24]}$. Due to this difference, the presence of $\mathrm{Ti}$ and $\mathrm{Si}$ at the surface of the Pt layer can reduce bismuth oxide to $\mathrm{Bi}$, which is volatile at 700 ${ }^{\circ} \mathrm{C}$. This hypothesis was confirmed by investigating the growth of SBT films directly on pure $\mathrm{Ti}$ and $\mathrm{Si}$ surfaces at $700{ }^{\circ} \mathrm{C}$ in oxygen. Under these conditions, there was practically no $\mathrm{Bi}$ incorporation during film growth. On the other hand, we demonstrated that there is an efficient $\mathrm{Bi}$ incorporation from the beginning of SBT growth on PtMgO substrates where there is no possibility that Ti or Si would appear on the Pt surface ${ }^{[23\}}$.

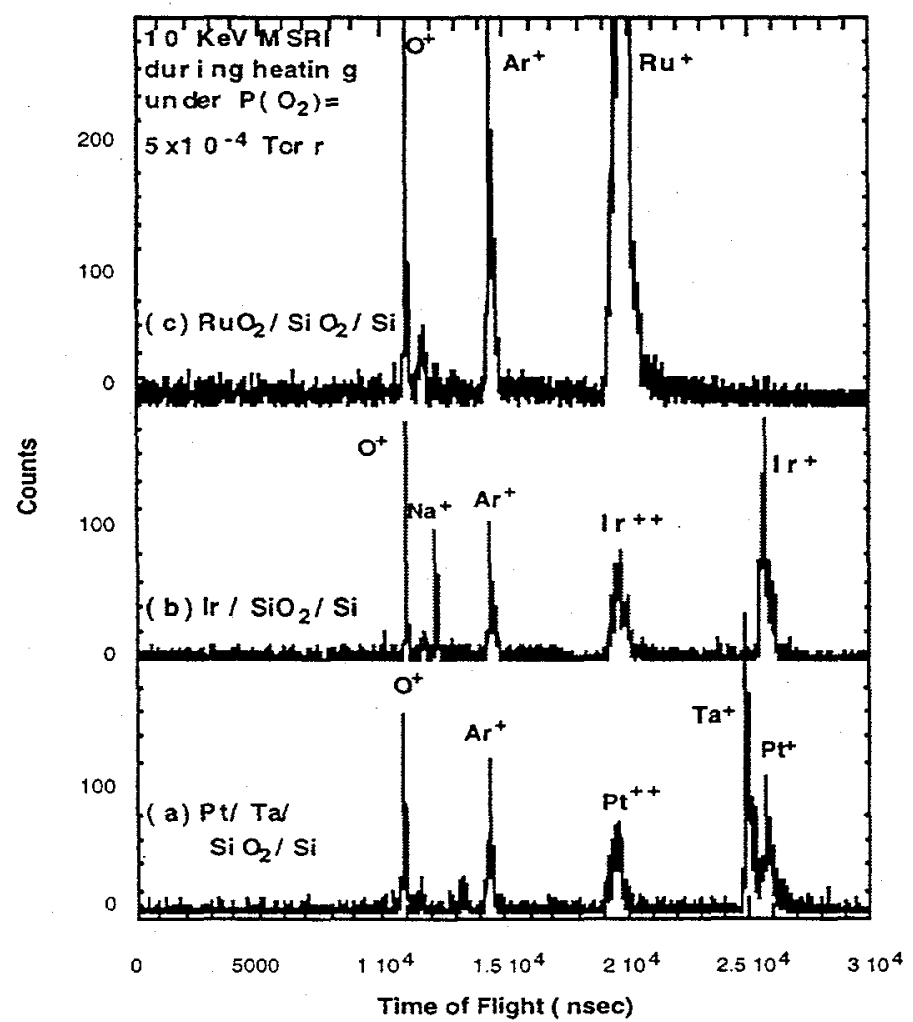

FIGURE 5. MSRI spectra from the analysis of $\mathrm{Pt} / \mathrm{Ta} / \mathrm{SiO}_{2} / \mathrm{Si}, \mathrm{Ir} / \mathrm{SiO}_{2} / \mathrm{Si}$, $\mathrm{RuO}_{2} / \mathrm{SiO}_{2} / \mathrm{Si}$ heterostructures during heating up to $700^{\circ} \mathrm{C}$ in oxygen $\left(\mathrm{P}\left(\mathrm{O}_{2}\right)=\right.$ $5 \times 10^{-4}$ Torr); the spectra were obtained using a $10 \mathrm{keV} \mathrm{Ar}{ }^{+}$primary ion beam. 


\section{O. AUCIELLO et al.}

We also investigated the growth of sputter-deposited SBT films on $\mathrm{Pt} / \mathrm{Ta} / \mathrm{SiO}_{2} / \mathrm{Si}, \quad \mathrm{Ir} / \mathrm{SiO}_{2} / \mathrm{Si}$, and $\mathrm{RuO}_{2} / \mathrm{SiO}_{2} / \mathrm{Si}$ at $700{ }^{\circ} \mathrm{C}$ in oxygen $\left(\mathrm{P}\left(\mathrm{O}_{2}\right)=5 \times 10^{-4}\right)$. MSRI analysis revealed that $\mathrm{Bi}$ is efficiently incorporated on $\mathrm{RuO}_{2}$ and Ir surfaces at all stages of the film growth, while the incorporation on $\mathrm{Pt} / \mathrm{Ta}$ electrodes is intermediate between that observed for Pt/Ti and that for Ir and $\mathrm{RuO}_{2}$ surfaces. Based on thermodynamic considerations, our interpretation is that $\mathrm{RuO}_{2}$ and Ir do not compete for oxygen with $\mathrm{Bi}$ species as effectively as $\mathrm{Ti}$ and $\mathrm{Si}$ species do, while $\mathrm{Ta}$ which has a smaller affinity for oxygen than $\mathrm{Ti}$, is less effective than $\mathrm{Ti}$ in competing with $\mathrm{Bi}$ for the available oxygen. This analysis correlates with our prior work, which demonstrated that $\mathrm{RuO}_{2}$ films are oxygen terminated ${ }^{[25]}$.

\section{COMPLEMENTARY IN SITU TOF-ISARS / SPECTROSCOPIC ELLIPSOMETRY (SE) STUDIES OF FILM SURFACE AND BURIED INTERFACES}

In this section, we discuss the synthesis of $\mathrm{Ba}_{\mathrm{x}} \mathrm{Sr}_{1-\mathrm{x}} \mathrm{TiO}_{3}$ (BST) as the vehicle to demonstrate the power of complementary in situ TOF-ISARS/SE characterization of film growth and interface processes. Research on $\mathrm{Ba}_{x} \mathrm{Sr}_{1}$. $\mathrm{TiO}_{3}$ thin films has recently intensified because of the multiple potential applications in high dielectric constant DRAMs, high frequency devices, and as possible gate oxides in metal-oxide-semiconductor field effect transistors (MOSFETs) ${ }^{[26,27]}$. Due to the progressive reduction in dielectric film thickness necessitated by ever-shrinking feature size in Si microcircuits, it is becoming more important to perform in situ characterization of the surface of films and buried interfaces of heterostructures, during film deposition, in order to understand and control critical growth processes. TOF-ISARS provides a wide range of information on the physics and chemistry of surfaces, but not on processes occurring at buried interfaces during film growth. Information on buried interface processes can be obtained with SE. Therefore, we have developed an integrated sputter-deposition/TOF-ISARS/SE system to investigate the processes described above ${ }^{[28]}$.

The dielectric properties of BST-based capacitors have been extensively investigated in recent years ${ }^{[29.30]}$. The work published in the literature indicate that the BST/bottom electrode interface and diffusion barriers underneath this electrode may play significant roles in controlling critical properties such as leakage and breakdown of BST capacitors. Therefore, it is important to understand bottom electrode/diffusion barrier heterostructure processes before and during BST deposition. For this purpose, we recently initiated a systematic series of studies on the growth of BST on different bottom electrode/barrier heterostructures. We discuss here initial results from studies of BST growth on Ir $/ \mathrm{TiN}$ heterostructures ${ }^{[28]}$, considered as candidates for integration of BST films with Si CMOS devices.

\section{Synthesis of BST Thin Films}

$\left(\mathrm{Ba}_{0.5}, \mathrm{Sr}_{0.5}\right) \mathrm{TiO}_{3}$ films were deposited by reactive ion beam sputtering using $\mathrm{Ar}^{+}$ions generated by a $3 \mathrm{~cm}$ Kaufman RF plasma ion source. The substrates used were $<001>\mathrm{MgO}$ single crystals and $\mathrm{Ir} / \mathrm{TiN} / \mathrm{SiO}_{2} / \mathrm{Si}$, the latter supplied by 
Motorola, with the Ir electrode deposited by RF magnetron sputtering and the TiN layer by chemical vapor deposition (CVD). The substrate temperature was kept at $700{ }^{\circ} \mathrm{C}$ during BST growth and subsequent post-deposition annealing. The BST films were synthesized via ion beam sputtering of a sintered $\mathrm{Ba}_{0.5} \mathrm{Sr}_{0.5} \mathrm{TiO}_{3}$ ceramic target. Details on substrate cleaning and preparation, and film deposition conditions can be found elsewhere ${ }^{[28]}$.

\section{TOF-ISARS and SE Characterization of Ir/TiN Electrodes and}

\section{BST Growth Processes}

We studied the stability of the $\mathrm{Ir} / \mathrm{TiN} / \mathrm{SiO} / \mathrm{Si}$ heterostructure (a candidate for integration of BST films with Si CMOS devices). The tests included annealing in $1 \times 10^{-4}$ Torr of oxygen at $700^{\circ} \mathrm{C}$ before deposition of the BST thin film. Fig 6 (a) shows an MSRI spectrum of the as-deposited Ir/TiN heterostructure. The spectrum revealed the presence of $\mathrm{H}^{+}, \mathrm{C}^{+}, \mathrm{Na}^{+}$, and other impurities, due mainly to atmospheric exposure. In addition, a small $\mathrm{Ti}$ peak and the Ir host peaks are present, indicating that there was slight segregation of $\mathrm{Ti}$ during the deposition of the Ir layer. MSRI spectra taken after 30 minutes annealing in oxygen (Fig. 6 (b)) show the disappearance of the Ir signal and strong reduction of all peaks shown in Fig. 6(a), simultaneously with the appearance of dominant Ti signal, indicative of a strong segregation of $\mathrm{Ti}$ to the surface of the Ir layer and that the Ir/TiN structure is not stable under heating in oxygen.

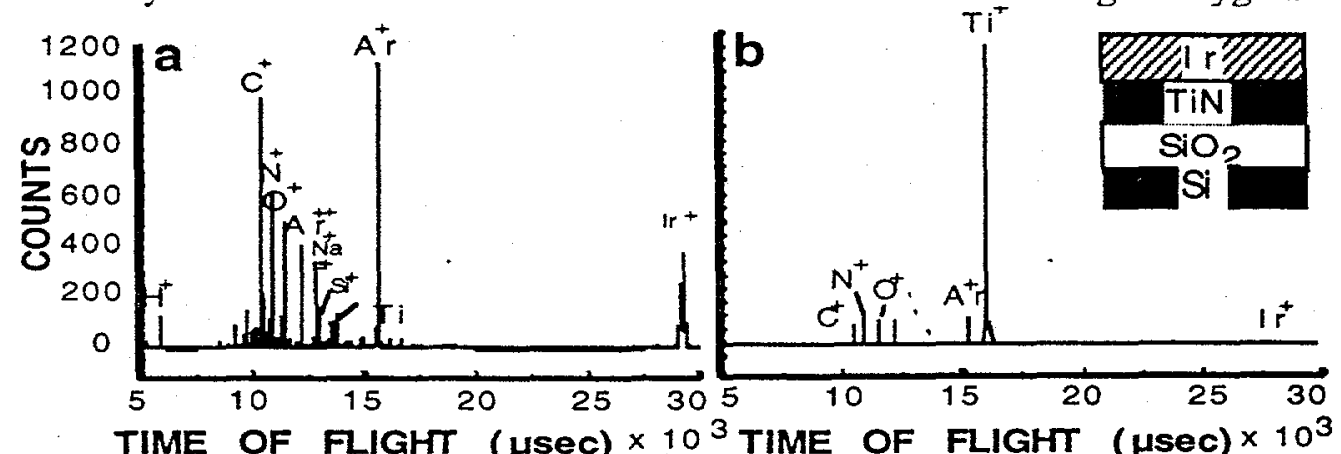

FIGURE 6. MSRI spectra of as-deposited (a) and oxygen annealed

$\left(5 \times 10^{-4} \mathrm{Torr}\right)$ at $700^{\circ} \mathrm{C}$ (b) $\mathrm{Ir} / \mathrm{TiN} / \mathrm{SiO}_{2} / \mathrm{Si}$ heterostructures ${ }^{[28]}$.

\section{SE System Calibration for Characterization of BST Film Growth}

In situ SE characterization of BST film growth processes requires an accurate determination of the optical constant of the BST film. Although some work has been reported ${ }^{[31]}$ on the optical properties of BST thin films, the results showed that the refractive index of BST films varies with different deposition techniques, and deposition and post-annealing temperature, which results in different densities and degrees of crystallization of the BST films. Therefore, it was necessary to characterize the optical properties of the BST films grown in our ion beam sputter-deposition system, before undertaking the studies of growth processes. To avoid the SE modeling complexity that may arise from the possible formation of a reaction interface layer between the BST film and substrate, $\left(\mathrm{Ba}_{0.5} \mathrm{Sr}_{0.5}\right) \mathrm{TiO}_{3}$ was deposited on $\mathrm{MgO}<001>$ single crystal substrates, resulting in a sharp BST/MgO interface ${ }^{[32]}$ because of the good thermal and chemical stability of $\mathrm{MgO}$. The oxygen deficiency and 
microstructural stability of BST films grown on $\mathrm{MgO}$ were investigated using sequential annealing in vacuum and oxygen at $700^{\circ} \mathrm{C}$. Real time SE was performed during each annealing cycle. No obvious changes in the SE spectra were observed before and after annealing. XRD analysis revealed that the ion beam sputter deposition technique produces good polycrystalline BST films at $700^{\circ} \mathrm{C}$. The surface roughness of the films was about $0.6 \mathrm{~nm}$, as measured by AFM. This roughness value was used in the SE modeling to extract the optical constants of the BST films on MgO. The refractive index (n) and extinction coefficient $(\mathrm{k})$ of our BST films agree with those expected for dense BST films ${ }^{[31]}$. We observed low optical absorption until near the band gap (about 3.4 $\mathrm{eV}$ ), as expected.

\section{In Situ Spectroscopic Ellipsometry Studies of Buried Interfaces during Growth of BST on Ir/TiN/SiO $2 / \mathrm{Si}$. Substrates}

We used in situ spectroscopic ellipsometry to study the buried interface between a BST film and an $\mathrm{Ir} / \mathrm{TiN} / \mathrm{SiO}_{2} / \mathrm{Si}$ substrate during ion beam sputter-deposition of BST at $700^{\circ} \mathrm{C}$ in $10^{-4}$ Torr of oxygen. The best fit of the SE model to the experimental data for the $\Psi$ and $\Delta$ ellipsometric parameters related to the BST/Ir system is achieved with the incorporation of an effective medium approximation (EMA) interface layer involving a mixture of $\mathrm{IrO}_{2}$ and Ir. This indicates that the Ir electrode is oxidized during the deposition of BST under the conditions specified above. The SE modeling results yield a thickness of $9.5 \mathrm{~nm}$ for the EMA interface layer formed after 60 minutes of BST deposition (Fig. 7). No evidence for a $\mathrm{TiO}_{2}$ layer was found, which indicates that the $\mathrm{Ti}$ that diffused to the Ir surface prior to BST deposition (Fig. 6(b)) was incorporated into the growing BST film. As a result, a slightly higher Ti content than stoichiometric composition could be expected in BST deposited on this substrate structure.

Because SE analysis is largely based on model-fitting to experimental data, it is necessary to use complementary techniques to confirm the information provided by SE. In this respect, the in situ MSRI analysis and complementary AFM characterization performed by us confirmed the SE analysis. Crosssection TEM studies and XPS depth profiling can also contribute to confirm the information provided by the SE studies and we will be doing these in the future.

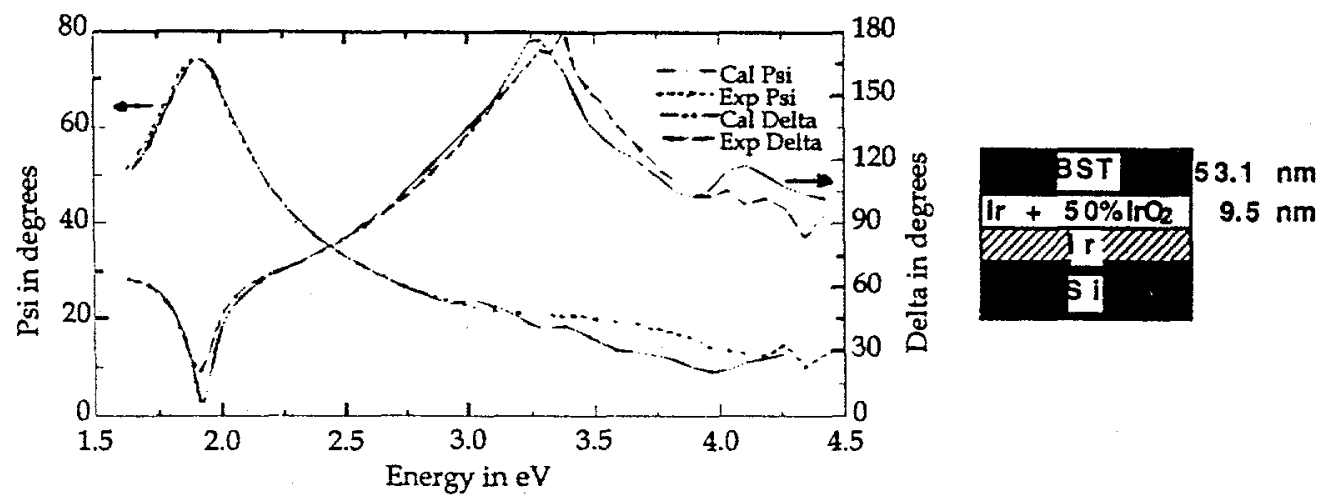

FIGURE 7. Experimental and calculated SE data for an as-deposited BST/Ir sample based on the best fit model, including the mean squared error (MSE) and the Ir layer thick enough to be considered as an opaque substrate. 
IN SITU STUDIES OF FERROELECTRIC FILMS AND DEVICEPROCESS

\section{CONCLUSIONS}

We have demonstrated that in situ and/or in situ, real-time characterization techniques can provide a wide range of information on thin film growth and interface processes critical to the development of materials integration strategies for the next generation of ferroelectric thin film-based devices.

TOF-ISARS demonstrated that: (a) $\mathrm{Ti}$ and $\mathrm{Si}$ atoms segregate to the surface of a $\mathrm{Pt} / \mathrm{Ti} / \mathrm{SiO}_{2} / \mathrm{Si}$ heterostructure when heated above $450^{\circ} \mathrm{C}$, while no such segregation is observed for the $\mathrm{Pt} / \mathrm{TiO}_{2} / \mathrm{SiO}_{2} / \mathrm{Si}$ heterostructure; (b) Some Ta segregation is observed in $\mathrm{Pt} / \mathrm{Ta} / \mathrm{SiO}_{2} / \mathrm{Si}$ heterostructures, but the extent of $\mathrm{Ta}$ segregation is much smaller than that of $\mathrm{Ti}$ in the $\mathrm{Pt} / \mathrm{Ti} / \mathrm{SiO} / \mathrm{Si}$ heterostructure; (c) The presence of segregated $\mathrm{Ti}$ and $\mathrm{Si}$ on the surface of the $\mathrm{Pt} / \mathrm{Ti} / \mathrm{SiO}_{2} / \mathrm{Si}$ heterostructure is associated with reduction and evaporative loss of metallic $\mathrm{Bi}$, resulting in inefficient incorporation of $\mathrm{Bi}$ during the early stages of SBT film growth; (d) an intermediate level of $\mathrm{Bi}$ incorporation is observed for the intial stages of SBT growth on $\mathrm{Pt} / \mathrm{Ta} / \mathrm{SiO} / \mathrm{Si}$ heterostructures; (e) $\mathrm{Bi}$ is incorporated very efficiently on $\mathrm{RuO}_{2} / \mathrm{SiO}_{2} / \mathrm{Si}$ structures. The results indicate that the choice of bottom electrode layers is critical for the growth of SBT films and their integration into Si substrates for the fabrication of NVFRAMs..

TOF-ISARS showed that there is a strong segregation of Ti to the surface of Ir in Ir/TiN bottom electrode heterostructures proposed as candidates for integration of BST with $\mathrm{Si}$ substrates, making the $\mathrm{Ir} / \mathrm{TiN}$ an unsuitable electrode heterostructure. In addition, the use of the complementary spectroscopic ellipsometry method revealed a partial oxidation of Ir bottom electrodes during growth of BST films by sputter-deposition in oxygen.

Our work has demonstrated that complementary in situ and in situ, realtime characterization techniques will play an ever increasing role in basic and applied research, not only in the field of ferroelectrics, but also in many others.

\section{Acknowledgments}

This work is supported by the U.S. Department of Energy, BES-Material Sciences, under Contract W-31-109-ENG-38; the National Science Foundation under Contract DMR 942-2182; the Office of Naval Research under Contract N00014-89-J-1178. We thank B. Melnick (Motorola) for the Ir/TiN samples.

\section{References}

[1.] A.R. Krauss, M. Rangaswamy, Y. Lin, D.M. Gruen, J.A. Schultz, H.K. Schmidt, and R.P.H. Chang, in "Multicomponent and Multilayered thin Films for Advanced Microtechnologies: Techniques, Fundamentals and Devices, O. Auciello and J. Engemann (Eds.), NATO/ASI Book Series vol 248 (Kluwer Academic Publishers, The Netherlands ,1993) p. 251.

[2.] O. Auciello, A.R. Krauss, and J. Im, in "Metal Oxides", topical issue of Annual Review of Materials Science, 28, 375 (1998).

[3.] L. Marchut, T.M. Buck, G.H. Wheatley, C.J. McMahon. Surf. Sci., 141, 549 (1984).

[4.] E. Taglauer, W. Englert, W. Heiland, and D. P. Jackson, Phys. Rev. Lett, 45, 740 (1980). 


\section{O. AUCIELLO et al.}

[5.] M.S. Hammond, J.A. Schultz, A.R. Krauss, J. Vac. Sci. Technol, A13, 1136 (1995).

[6.] R.S. Bhattacharya,W. Eckstein, H. Verbeek, Surf. Sci.,93,563 (1980).

[7.] J.W. Rabalais, J. Chen, J. Chem. Phys., 85, 3617 (1986).

[8.] H.K. Schmidt, L.R. Anderson, and J.A. Schultz, Appl. Surf. Sci., 35, 274 (1988-89).

[9.] J.A. Schultz and H.K. Schmidt, US Patent \# 5,087,815 (1992).

[10.] V.S. Smentkowski, A.R. Krauss, D.M. Gruen, J.C. Holecek, and J.A. Schultz, J. Vac. Sci. Technol., A16, 1779 (1998).

[11.] A.R. Krauss, A. Dhote, O. Auciello, S. Aggarwal, R. Ramesh, and D.M. Gruen, Integrated Ferroelectrics (these proceedings).

[12.] J. Im, A.R. Krauss, Y. Lin, J.A. Schultz, O. Auciello, D.M. Gruen, R.P.H. Chang, Nucl. Instrum. Meth. B118, 772 (1996).

[13.] H.K. Schmidt, J.A. Schultz, Z. Zheng, Diamond and Diamond-Like Coatings, R.E. Clausing (Ed.) (New York: Plenum Press, (1991) p. 669.

[14.] O. Auciello, A.R. Krauss, J. Im, D.M. Gruen, E.A. Irene, R.P.H. Chang, and G.E. McGuire, Appl. Phys. Lett., 69, 2671 (1996).

[15.] J. Im, O. Auciello, and A.R. Krauss (to be published, 1999).

[16.] A.R. Krauss, O. Auciello, J.A. Schultz, MRS Bulletin, 20, 18 (1995).

[17. [ A.R. Krauss, J. Im, J.A. Schultz, V.S. Smentkowski, K. Waters, C.D. Zuiker, D.M. Gruen, R.P.H. Chang, Thin Solid Films, 270, 130 (1995).

[18.] O. Auciello, Integrated Ferroelectrics, 15, 211 (1997).

[19.] K. Sreenivas, I. Reaney, T. Maeder, N. Setter, C. Jagadish, and R.G. Elliman, J. Appl. Phys. 75, 232 (1994).

[20.] R. Bruchhaus, D. Pitzer, O. Eibl, U. Scheithauer, and W. Hoesler, Mat. Res. Soc. Symp. Proc., 243, 123 (1992).

[21.] G. Schindler, W. Hartner, V. Joshi, N. Solayappan, G. Derbenwick and C. Mazure, Integrated Ferroelectrics, 17, 421 (1997).

[22.] J. T. Evans Jr., L.L. Boyer and N B. Velasquez, presented at the 9th International Meeting on Ferroelectricity, Seoul, Korea, 1997.

[23.] J. Im, O. Auciello, A.R. Krauss, A. Dhote, D.M. Gruen, R.Ramesh and R.P.H. Chang, Appl. Phys. Lett., 72, 2529 (1998).

[24.] Darken LS, Gurry RW, Physical Chemistry of Metals, McGraw-Hill, New York (1953)

[25.] Y. Lin, A.R. Krauss, O. Auciello, Y. Nishino, D.M. Gruen, J.A. Schultz, and R.P.H. Chang, J. Vac. Sci. Technol. A 12, 1557 (1994).

[26.] D. E. Kotecki, Semiconductor International Nov, 109 (1996).

[27.] P. Balk, J. Non-Cryst. Solids 187, 1 (1995).

[28.] Y. Gao, A. H. Mueller, E. A. Irene, O. Auciello, A.R. Krauss, and J. A. Schultz, J. Vac. Sci. Technol A (in press, 1999).

[29.] T. Kuroiwa, Y. Tsunemine, T. Horikawa, T. Makita, J. Tanimura, N. Mikami, and K. Sato, Jpn. J. Appl. Phys. Part 1 33, 5187 (1994).

[30.] RECENT REVIEW BY STREIFFER ET AL.

[31.] I. Suzuki, M. Ejima, and K. Watanabe Y. M. Xiong, and T. Saitoh, Thin Solid Films 313-314, 214 (1998).

[32.] R. Thielsch, K. Kaemmer, B. Holzapfel, and L. Schultz, Thin Solid Films 301, 203 (1997). 